\title{
Simultaneous ground and satellite observations of an isolated proton arc at subauroral latitudes
}

Sakaguchi, K., K. Shiokawa, A. Ieda, Y. Miyoshi, Y. Otsuka, and T. Ogawa

Solar-Terrestrial Environment Laboratory, Nagoya University, Toyokawa,

Japan

M. Connors

Centre for Science, Athabasca University, Athabasca, Alberta, Canada

E. F. Donovan

Department of Physics and Astronomy, University of Calgary, Calgary,

Alberta, Canada

F. J. Rich

Air Force Research Lab (VSBXP), Hanscom AFB, MA, USA

K. Sakaguchi, K. Shiokawa, A. Ieda, Y. Miyoshi, Y. Otsuka and T. Ogawa, Solar-Terrestrial Environment Laboratory, Nagoya University, Toyokawa, Aichi 442-8507 Japan. (kaori@stelab.nagoya-u.ac.jp; shiokawa@stelab.nagoya-u.ac.jp; ieda@stelab.nagoyau.ac.jp; miyoshi@stelab.nagoya-u.ac.jp; otsuka@stelab.nagoya-u.ac.jp; ogawa@stelab.nagoyau.ac.jp)

M. Connors, Centre for Science, Athabasca University, Athabasca, Alberta, Canada. (martinc@athabascau.ca) 
Abstract. We observed an isolated proton arc at the Athabasca station (MLAT: $62^{\circ} \mathrm{N}$ ) in Canada on 5 September, 2005, using a ground-based allsky imager at wavelengths of $557.7 \mathrm{~nm}, 630.0 \mathrm{~nm}$, and $486.1 \mathrm{~nm}(\mathrm{H} \beta)$. This arc is similar to the detached proton arc observed recently by the IMAGE satellite [Immel et al., 2002]. The arc appeared at 0500-0700 UT (2100-2300 MLT) coincident with strong Pc 1 geomagnetic pulsations in the frequency range of the electromagnetic ion cyclotron (EMIC) wave. A small substorm took place at $0550 \mathrm{UT}$, while the isolated arc did not change its structure and intensity before and after the substorm onset. From particle data obtained by the NOAA 17 satellite, we found that the isolated arc was located in the localized $(\mathrm{L} \sim 4)$ enhancement of ion precipitation fluxes at an energy range of 30-80 keV. Trapped ion flux enhancements (ring current ions) were also observed at two latitudinally separated regions. The localized ion precipitation was located at the outer boundary of the inner ring current ions. The DMSP F13 satellite observed signatures of ionospheric plasma trough near the conjugate point of the arc in the southern hemisphere. The trough is considered to be connected to the plasmapause. These results indicate that the source region of the isolated arc was located near the plasmapause and

E. F. Donovan, Department of Physics and Astronomy, University of Calgary, Calgary, Alberta, Canada. (eric@phys.ucalgary.ca)

F. J. Rich, Air Force Research Lab (VSBXP), Hanscom AFB, MA, 01731-3010, USA. (frederick.rich@hanscam.af.mil) 
SAKAGUCHI ET AL.: SIMULTANEOUS OBSERVATIONS OF AN ISOLATED PROTON ARC $\quad \mathrm{X}-3$ in the ring current. We conclude that the observed isolated proton arc at subauroral latitudes were driven by the EMIC waves, which were generated near the plasmapause and scattered the ring current protons resonantly into the loss cone. 


\section{Introduction}

The hydrogen Balmer series emissions $(\mathrm{H} \alpha$ and $\mathrm{H} \beta)$ in the aurora were first observed from the ground more than a half century ago at Oslo [Vegard, 1939]. The $\mathrm{H} \alpha$ and $\mathrm{H} \beta$ lines in the proton aurora are emitted by neutral hydrogen atoms in excited states through the charge-exchange interactions in the upper atmosphere. The characteristics of these lines are different from those in the electron aurora. In particular, the center wavelength of these lines observed from the ground along a magnetic field line is shorter than the center wavelength of the normal lines due to the Doppler shift of the emission from precipitating hydrogen atoms with considerable velocities [Vegard, 1948; Meinel, 1951]. The early study of the proton aurora since its discovery to the late 1960s was reviewed by Eather [1967]. The emission lines usually observed in the electron aurora are also observed in the proton aurora, because the neutral atmosphere is excited by energetic precipitating protons [Eather, 1968].

Recently, global images of proton aurora have been provided by the Far Ultraviolet (FUV) Spectrographic Imager (SI) on board the Imager for Magnetopause-to-Aurora Global Exploration (IMAGE) satellite [Burch, 2000; Mende et al., 2000]. The IMAGEFUV camera observed several proton arc events detached to the equatorward from the main proton oval at subauroral latitudes over several hours of local time in the afternoon sector [Immel et al., 2002]. This phenomenon was called 'detached proton arc'. In the past, the events, which were called the detached arc, were reported during the ISIS 2 mission as phenomena due to electron precipitation at the dusk-evening sector at subauroral latitudes [Anger et al., 1978; Moshupi et al., 1979]. Particle data from ISIS-2 indicated 
SAKAGUCHI ET AL.: SIMULTANEOUS OBSERVATIONS OF AN ISOLATED PROTON ARC $\quad \mathrm{X}-5$ that detached arcs were excited by electrons rather than by ions [Wallis et al., 1979]. On the other hand, the data from the IMAGE satellite provide strong evidence that proton precipitation is the main component of the detached arcs [Immel et al., 2002]. Using lowaltitude satellites, mean energies of precipitating protons into the subauroral detached arc were found to be 20-30 keV. Subauroral proton arcs appear in the afternoon sector during geomagnetically disturbed periods when the interplanetary magnetic field rotates either from south to north or from west to east and when the magnetosphere is moderately compressed [Burch et al., 2002]. An observation of direct link between a detached subauroral proton arc and a globally observed plasmaspheric plume was first reported by Spasojevic et al. [2004]. The mechanism and the condition responsible for driving the proton precipitation are often considered that ion cyclotron waves scatter protons into the loss cone in the interaction between cold plasmaspheric particles and energetic ring-current particles.

The magnetic pulsations in the $\mathrm{Pc}_{\mathrm{c}} 1$ and $\mathrm{Pc} 5$ frequency range were observed in the vicinity of detached proton arc [Immel et al., 2005]. The Pc 1 magnetic pulsations has a similar frequency to that of the ion cyclotron waves in the equatorial plane. A close relationship between the localized (within $\sim 1^{\circ}$ in latitude) enhancement of proton $(>30$ $\mathrm{keV}$ ) precipitation observed by low-altitude satellites and the Pc 1 pulsation recorded on the ground was reported by Yahnina et al. [2000, 2002] in the subauroral region. Their findings support the ion cyclotron mechanism of the Pc 1 generation according to which both wave generation and particle scattering occur in the source region. However, there have been no simultaneous observations of proton precipitation, proton arc, and $\mathrm{Pc} 1$ geomagnetic pulsation at subauroral latitudes yet. 
In this paper, we report ground-based observation of an isolated proton arc, which appeared when an intense geomagnetic Pc 1 pulsation were observed in the premidnight sector at 1830-2300 MLT. The arc corresponds to a localized enhancement of the precipitating ions which was isolated equatorward from the main ion oval. This isolated proton arc is fairly similar to the detached proton arc observed by the IMAGE satellite.

\section{Observation}

We have been conducting auroral observation using a high sensitive all-sky imager, an induction magnetometer, and a meridian-scanning filter-tilting photometer at Athabasca, Canada since September, 2005. Athabasca $\left(54.7^{\circ} \mathrm{N}, 246.7^{\circ} \mathrm{E}\right.$, magnetic latitude (MLAT): $62.0^{\circ} \mathrm{N}$ ) is located in the subauroral region at $\mathrm{L} \sim 4$. The imager and the photometer are parts of the Optical Mesosphere Thermosphere Imagers (OMTIs) [Shiokawa et al., 1999, 2000]. The all-sky imager uses a thinned and back-illuminated cooled charge coupled device $(\mathrm{CCD})$ with $512 \times 512$ pixels and has seven interference filters which transmit wavelengthes of 557.7-nm (O, filter bandwidth: $1.76 \mathrm{~nm}$ ), 630.0-nm (O, $1.64 \mathrm{~nm}), 720-910$ nm (inflared OH-band), 486.1-nm (H $\beta, 1.32 \mathrm{~nm})$, 572.5-nm (background), 844.6-nm (O, $1.30 \mathrm{~nm})$, and $589.3-\mathrm{nm}(\mathrm{Na}, 1.56 \mathrm{~nm})$. In this study, we use auroral images with a time resolution of 2 min for $557.7-\mathrm{nm}, 630.0-\mathrm{nm}$, and $\mathrm{H} \beta$, which have exposure times of $5 \mathrm{~s}$, $15 \mathrm{~s}$, and $25 \mathrm{~s}$, respectively. We take $2 \times 2$ binning of the CCD pixels $(256 \times 256$ in total $)$. The induction magnetometer measures variations of three-component geomagnetic field with a sensitivity of $0.45[\mathrm{~V} / \mathrm{nT}]$ at $6 \mathrm{~Hz}$ with a turnover frequency $\sim 6 \mathrm{~Hz}$.

Figure 1 shows interplanetary and ground auroral/field variations during the isolated proton arc event of 5 September, 2005. Figure 1a-1d show proton density $\left[\mathrm{cm}^{-3}\right]$, GSM-X component of solar wind velocity [km/sec], and GSM-Z and GSM-Y components of inter- 
SAKAGUCHI ET AL.: SIMULTANEOUS OBSERVATIONS OF AN ISOLATED PROTON ARC X - 7 planetary magnetic field (IMF) variations, respectively, obtained by the ACE spacecraft at $X=219 R_{E}$. These data are shifted 43 min by taking the travel time from the ACE spacecraft to the ground into account. Figures $1 \mathrm{e}-1 \mathrm{~g}$ show north-south cross sections (keograms) of auroral structure for $557.7 \mathrm{~nm}, 630.0 \mathrm{~nm}$, and $\mathrm{H} \beta$ observed by the all-sky imager at Athabasca. The vertical axis of keogram is converted from all-sky coordinates to the geographical coordinates, assuming auroral altitudes of $120 \mathrm{~km}$ for $557.7 \mathrm{~nm}$ and $\mathrm{H} \beta$ and $200 \mathrm{~km}$ for $630.0 \mathrm{~nm}$. The keogram shows variations of auroral intensity at a geographical longitude of Athabasca $\left(246.7^{\circ} \mathrm{E}\right)$. Figure $1 \mathrm{~h}$ shows $\mathrm{X}$, Y, and Z components of magnetic field variations at Meanook, which is 17-km southwest of Athabasca. Figure 1i shows dynamic spectrum of $\mathrm{H}$ component geomagnetic field variations observed by the induction magnetometer at Athabasca in the frequency range of 0.10-32 Hz.

An isolated arc appeared at 0500-0640 UT in all the three emissions in Figures 1e-1g. The arc moved equatorward gradually from $53.5^{\circ} \mathrm{N}$ to $51^{\circ} \mathrm{N}\left(\mathrm{MLAT}=61.2^{\circ}-58.8^{\circ}\right)$. Only the arc in 630.0-nm emission lasted until 0740 UT. The sky of Athabasca was cloudy before 0500 UT. Thus, the start time of the isolated arc was unclear. A small auroral substorm took place at 0550-0700 UT, as characteraized by the intense auroral emissions in the northern sky of the keograms in Figures 1e-1g and by magnetic field variations in Figure 1h. The growth phase of the substorm seems to start from 0400 UT, when the IMF-Bz turns to negative. The isolated arc did not change its structure and intensity before and after the substorm onset.

A strong Pc 1 geomagnetic pulsation was observed by the induction magnetometer at Athabasca at 0230-0730 UT, as shown in Figure 1i. The frequency of Pc 1 increased from $0.3 \mathrm{~Hz}$ to $1.0 \mathrm{~Hz}$ from $0230 \mathrm{UT}$ to $0730 \mathrm{UT}$. At the starting time of the Pc 1 pulsation 
IMF-By suddenlly increased from zero to $\sim 4 \mathrm{nT}$, and lasted to be positive (eastward) until 1100 UT, as shown in Figure 1d. The intensity of this Pc 1 pulsation was most intense compared with those observed at Athabasca during September-October, 2005.

During the isolated arc event in Figure 1, the NOAA 17 satellite crossed the western edge of the arc from low to high latitudes. Figure 2 shows ground-based auroral images $\left(10^{\circ} \times 10^{\circ}\right.$ in latitude and longitude, $1135 \mathrm{~km} \times 656 \mathrm{~km}$ in horizontal distances $)$ obtained at Athabasca from 0456:02 to 0502:36 UT on 5 September, 2005. The images have been converted from the original all-sky coordinates to geographical coordinates by assuming auroral altitudes of $120 \mathrm{~km}$ for $557.7 \mathrm{~nm}$ and $\mathrm{H} \beta$ and $200 \mathrm{~km}$ for $630.0 \mathrm{~nm}$. Geomagnetic north is $18^{\circ}$ westward from geographic north. The image center is the zenith of Athabasca. The red lines and squares indicate the track and footprints of the NOAA 17 satellite, respectively.

In Figure 2, an auroral arc extends from east to west at a latitude of $53^{\circ} \mathrm{N}\left(62.6^{\circ} \mathrm{N}\right.$ MLAT). The arc width is less than $1^{\circ}$ in latitude. The arc seen in the $630.0-\mathrm{nm}$ images is located east side compared with that in the 557.7-nm and $\mathrm{H} \beta$ images. The NOAA satellite footprint crossed the western edge of the arc from low to high latitudes at 0458:36 UT.

The NOAA 17 satellite is in a circular polar orbit at an altitude of about $800 \mathrm{~km}$. The satellite measures precipitating and trapped electrons and ions with energies less than $20 \mathrm{keV}$ using the TED (Total Energy Detector) and larger than $30 \mathrm{keV}$ using the MEPED (Medium Energy Proton and Electron Detector) [Evans and Greer, 2000]. At high latitudes $(L>3)$ the orientation of the MEPED allows to observe the particles both within the loss cone (precipitating particles) and outside the loss cone (locally trapped particles). 
SAKAGUCHI ET AL.: SIMULTANEOUS OBSERVATIONS OF AN ISOLATED PROTON ARC X - 9

Figure 3 shows electron and ion energy spectra during the arc crossing shown in Figure

2. Figures $3 \mathrm{a}-3 \mathrm{~d}$ are the precipitating $\left(\sim 70^{\circ}\right.$ to the horizontal plane $)$ and trapped $\left(\sim 10^{\circ}\right.$ to the horizontal plane) electron and ion spectra at 30-2500 keV (electrons) and 30-6900 $\mathrm{keV}$ (ions) observed by the MEPED instruments. Figures 3e-3h are the precipitating electron and ion spectra at energies less than $20 \mathrm{keV}$ observed by the TED instruments at angles of about $\sim 75^{\circ}$ and $\sim 50^{\circ}$ to the horizontal plane. The vertical dashed line indicates the time (0458:36 UT) when the NOAA 17 footprint crossed the isolated arc, as shown in Figure 2. The dashed line lies on a localized enhancement of energetic ion precipitation mainly at energes of $30-80 \mathrm{keV}$, as shown in Figure $3 \mathrm{~b}$. This localized ion precipitation is separated from the main ion precipitating region at latitudes higher than $64^{\circ}$ MLAT. Figure $3 \mathrm{~d}$ shows that the region of trapped ions $(30-250 \mathrm{keV})$, which probably correspond to the ring current, is separated into the two regions, at $\sim 59^{\circ}-62^{\circ}$ MLAT and $\sim 64^{\circ}-69^{\circ}$ MLAT. These two belts may be a consequence of previous two injections. Actually there were substorm-like magnetic activities at 0050-0230 UT on 5 September in high-latitude magnetic field data. The dashed line and the localized ion precipitation in Figure $3 \mathrm{~b}$ are lacated at the poleward boundary of the lower-latitude ring-current ion belt. Figure $3 f$ shows that ions at energies below $20 \mathrm{keV}$ also precipitate in the isolated arc region with a wider latitudinal range of $\sim 59^{\circ}-63^{\circ}$ MLAT. A weak electron precipitaion at energies below $20 \mathrm{keV}$ is also seen in Figure 3e at the isolated arc latitudes. Electrons precipitate significantly in the higher latitudes above $65^{\circ}$ MLAT.

During the present arc event, the DMSP F13 satellite also crossed nearly the conjugate point of the arc in the southern hemisphere from high to low latitudes at 0627-0628 UT. Figure 4 shows the $\mathrm{H} \beta$ arc image at $0628 \mathrm{UT}$ with the DMSP satellite footprints. The 
IGRF-2005 model was used to map the satellite location to the conjugate hemisphere. The line and the squares indicate the track and footprints of the DMSP satellite, respectively, every 20-min at an altitude of 120-km. The satellite probably crossed the arc at 0627:200628:00 UT out of the field of view of the image.

Figure 5 shows electron and ion temperatures, ion drift velocity perpendicular to the satellite track, ion density, and precipitating electron and ion energy spectra obtained by the DMSP F13 satellite at an altitude of $840 \mathrm{~km}$ at 0626:03-0629:03 UT on 5 September, 2005. The time interval of possible arc crossing in Figure 4 is shown by the two dashed lines. The arc occurred at the region of increasing electron temperature and decreasing ion density. The horizontal plasma velocity turns from east to west in this region, and a strong westward drift with a maximum speed of $\sim 1000 \mathrm{~m} / \mathrm{s}$ was observed. This region corresponds to the equatorward boundary of precipitating electrons and ions. Flux enhancements corresponding to the isolated arc are not seen in these electron and ion energy spectra.

\section{Discussion}

In this paper, we investigate relations among an isolated proton arc, precipitating particles, and Pc 1 geomagnetic pulsations, observed at subauroral latitudes of $\sim 60^{\circ} \mathrm{MLAT}$. The isolated proton arc appeared in the premidnight sector at 21-23 MLT for about two hours. The latitudinal width of the isolated arc was less than $1^{\circ}$. The arc moved equatorward gradually from $61.2^{\circ}$ MLAT to $58.8^{\circ}$ MLAT. Before and during the arc appearance, strong Pc 1 geomagnetic pulsations were observed at the same ground station. The frequency of Pc 1 geomagnetic pulsations gradually increased from $0.3 \mathrm{~Hz}$ to $1.0 \mathrm{~Hz}$. Data from the NOAA 17 satellite shows that precipitating particles into the isolated arc were 
SAKAGUCHI ET AL.: SIMULTANEOUS OBSERVATIONS OF AN ISOLATED PROTON ARC X - 11 energetic ions at energies of $30-80 \mathrm{keV}$. This enhancement of precipitation ion flux was separated equatorward from the main ion oval. Data from the DMSP F13 satellite at conjugate point of the arc show ion density reduction and electron temperature enhancement, which are the signatures of the ionospheric plasma trough. This result suggests that the magnetospheric source of the isolated arc was located near the plasmapause. The DMSP F13 also observed on intense westward ion drift, similar to the subauroral ion drift (SAID) [Spiro et al., 1979].

The isolated arc observed from our ground-based imager is similar to the detached proton arc observed by the IMAGE satellite at latitudes equatorward of the main proton oval. Presence of precipitating protons and absence of precipitating electrons are associated with the detached proton arc [Immel et al., 2002; Burch et al.,2002]. Immel et al. [2005] considered that the driving mechanism of the energetic proton precipitation to the detached arc is the electromagnetic ion-cyclotron (EMIC) waves, which are generated through the interaction between the thermal plasma in the plasmasphere and more energetic ring current ions, and scatter protons into the loss cone. Immel et al. [2005] observed enhancements of wave activity at ion-cyclotron frequencies using a ground-based magnetometer at nearly conjugate point of the detached arcs. In this paper, we observed intense Pc 1 geomagnetic pulsation in the frequency range of the EMIC waves and energetic ion precipitation coincident with the isolated ion arc.

For the present isolated arc event, data from the DMSP satellite show signatures of the ionospheric plasma trough in the vicinity of the isolated proton arc. The trough corresponds to the plasmapause in the magnetosphere [e. g., Yizengaw et al., 2005]. By the NOAA 17 satellite, two-separated regions of trapped ion flux enhancements were 
observed, and ion precipitation was observed at the outward boundary of the inner ring current. Ion-cyclotron resonant interactions, which generate the EMIC wave, often occur in the ring current region because of anisotropic pitch-angle distribution of charged ring current particles due to the loss cone or temperature anisotropy. Model calculations by Kozyra et al. [1984] and Jordanova et al. [2001] show that growth rate of the EMIC wave reach maximum near the plasmapause.

The EMIC wave is efficiently scatters energetic ring current ions resonantly into the loss cone and thus represents an important ring current loss mechanism [Kennel and Petschek, 1966; Cornwall et al., 1970]. Energy and momentum exchange can occur when the Doppler shifted wave frequency matches the cyclotron frequency of the individual resonant particles. Recently, Erlandson and Ukhorskiy [2001] found using the data from the Dynamic Explorer 1 satellite that the proton flux in the loss cone was correlated with the EMIC wave spectral density. Yahnina et al. [2000; 2002] found a close relation between ground-based observations of Pc 1 geomagnetic pulsations and satellite in-situ observations of localized enhancement of precipitating energetic protons.

In this paper, we also observed a localized enhancement of energetic ion precipitations that caused the isolated arc together with the Pc 1 geomagnetic pulsation. The isolated arc initially appeared at $61.2^{\circ}$ MLAT, and moved to lower latitudes to $58.8^{\circ}$ MLAT. Using IGRF-2005 model, magnetic field strengths at the equatorial plane are estimated to be $405.5 \mathrm{nT}$ and $630.2 \mathrm{nT}$ for $61.2^{\circ}$ MLAT and 58.8 MLAT, respectively. The ion cyclotron frequencies at $405.5 \mathrm{nT}$ and $630.2 \mathrm{nT}$ are $6.2 \mathrm{~Hz}$ and $9.6 \mathrm{~Hz}$ for $\mathrm{H}^{+}, 1.5 \mathrm{~Hz}$ and $2.4 \mathrm{~Hz}$ for $\mathrm{He}^{+}$, and $0.4 \mathrm{~Hz}$ and $0.6 \mathrm{~Hz}$ for $\mathrm{O}^{+}$. The observed frequency of the $\mathrm{Pc}$ 1 geomagnetic pulsation at the time of the isolated arc appearance was $0.6 \mathrm{~Hz}$. The 
SAKAGUCHI ET AL.: SIMULTANEOUS OBSERVATIONS OF AN ISOLATED PROTON ARC X - 13 frequency went up gradually to $1.0 \mathrm{~Hz}$ when the arc disappeared. These EMIC waves are in the frequency range between $\mathrm{O}^{+}$and $\mathrm{He}^{+}$gyrofrequencies at the equatorial plane. According to the arc motion, the frequencies estimated from the model calculation become 1.55 times larger from $61.2^{\circ}$ MLAT to $58.8^{\circ}$ MLAT. The change of the observed frequency of Pc 1 geomagnetic pulsations is $\sim 1.66(=1.0 \mathrm{~Hz} / 0.6 \mathrm{~Hz})$, which is comparable to the model calculation. Therefore, the equatorward movement of the isolated arc seems to be consistent to the increase of the Pc 1 frequency.

\section{Conclusion}

Using simultaneous data set obtained by a multi-channel all-sky imager, an induction magnetometer, the NOAA 17 satellite, and the DMSP F13 satellite, we have investigated generation mechanism of an isolated proton arc observed on 5 September, 2005, at Athabasca, Canada (MLAT $\sim 62^{\circ} \mathrm{N}, \mathrm{L} \sim 4$ ). The observed characteristics can be summarized as follows:

1. An isolated proton arc (wavelengthes at $557.7 \mathrm{~nm}, 630.0 \mathrm{~nm}$, and $\mathrm{H} \beta$ ) was observed in the premidnight sector at 0500-0700 UT (2100-2300 MLT) at $~ 59^{\circ}-61^{\circ}$ MLAT.

2. The arc was not effected by a small substorm that took place at $0550 \mathrm{UT}$.

3. Strong Pc 1 geomagnetic pulsations were simultaneously observed at frequencies of 0.30-1.0 Hz at 1830-2300 MLT

4. The NOAA 17 satellite observed a localized enhancement of precipitating ions at energies of $30-80 \mathrm{keV}$ with a narrow latitudinal width at the latitude of the arc. The satellite also observed trapped ring current ions separated into two latitudinal belts. The 
ion precipitation associated with the isolated arc was located near the outer boundary of the inner ring current belt.

5. The DMSP F13 satellite observed signatures of the ionospheric plasma trough (decrease in ion density and increase in electron temperature) and intense westward plasma drift near the conjugate point of the isolated arc in the southern hemisphere.

These observations supports the following scenario of the generation of the isolated arc: Ring current particles, which were isolated from the main ring current, trigger the ion cyclotron instability in the vicinity of the plasmapause. This instability generates the EMIC waves, which scatter the energetic protons resonantly into the loss cone to cause the observed isolated proton arc. The EMIC waves were observed as strong Pc 1 geomagnetic pulsations by the ground-based induction magnetometer. From model calculations we found that the equatorward movement of the arc was consistent to the observed increase of the Pc 1 frequencies. The arc would have a narrow latitudinal width at a subauroral latitude, since coexistence of both the ring current ions and plasmapause is needed for generation of the EMIC waves.

Acknowledgments. We thank Y. Katoh, M. Satoh, and T. Katoh of the SolarTerrestrial Environment Laboratory, Nagoya University, for their kind support of auroral imaging and geomagnetic observations. The magnetic field data at Meanook were obtained from the Geological Survey of Canada (GSC).

\section{References}

Anger, C. D., M. C. Moshupi, D. D. Wallis, J. S. Murphree, L. H. brace and, G. G. Shepherd, Detached auroral arcs in the trough region, J. Geophys. Res., 83, 2683-2689, 
SAKAGUCHI ET AL.: SIMULTANEOUS OBSERVATIONS OF AN ISOLATED PROTON ARC X - 15 1978.

Yizengaw, E., H. Wei, M. B. Moldwin, D. Galvan, L. Mandrake, A. Mannucci, and X. Pi, The correlation between mid-latitude trough and plasmapause, Geophys. Res. Lett., 32, L10102, 2005.

Burch, J. L., IMAGE mission overview, Space Sci. Rev., 91, 1-14, 2000.

Burch, J. L., W. S. Lewis, T. J. Immel, P. C. Anderson, H. U. Frey, S. A. Fuselier, J. C. Gerard, S. B. Mende, D. G. Mitchell, and M. F. Thomsen, Interplanetary magnetic field control of afternoon-sector detached proton auroral arcs, J. Geophys. Res., 10\%, $17-1,2002$.

Cornwall, J. M., F. V. Coroniti, and R. M. Thorne, Turbulent loss of ring current protons, J. Geophys. Res., 75, 4699, 1970.

Eather, R. H., Auroral proton precipitation and hydrogen emissions, Rev. Geophys., 5, 207, 1967.

Eather, R. H., Spectral Intensity Ratios in Proton-Induced Auroras, J. Geophys. Res., 73, $119,1968$.

Erlandson, R. E. and A. J. Ukhorskiy, Observations of electromagnetic ion cyclotron waves during geomagnetic storm: Wave occurrence and pitch angle, J. Geophys. Res., 106, 3883-3895, 2001.

Evans, D. S., and M. S. Greer, Polar orbiting environmental satellite space environment monitor: 2. Instrument descripition and archive data documentation, NOAA Tech. Memo. OAR SEC-93, Natl. Oceanic and Atmos. Admin., Boulder, Colo.

Immel, T. J., S. B. Mende, H. U. Frey, L. M. Peticolas, C. W. Carlson, J. Gerard, B. Hubert, S. A. Fuselier and, J. L. Burch, Precipitation of auroral protons in detached 

arcs, Geophys. Res. Lett., 29, 14-1, 2002.

Immel, T. J., S. B. Mende, H. U. Frey, J. Patel, J. W. bonnell, M. J. Engebretson, and S. A. Fuselier, ULF waves associated with enhanced subauroral proton precipitation, Americal Geophysical Union, Geophysical Monograph Series 159, 71-84, 2005.

Jordanova, V. K., C. J. Farrugia, R. M. Thorne, G. V. Khazanov, G. D. Reeves, and M. F. Thomsen, Modeling ring current proton precipitation by electromagnetic ion cyclotron waves during the May 14-16, 1997, storm, J. Geophys. Res., 106, 7-22. 2001

Kennel, C. F., and H. E. Petscheck, Limit on stably trapped particle fluxes, J. Geophys. Res., 71, 1, 1966.

Kozyra, J. U., T. E. Cravens, A. F. Nagy, E. G. Fontheim, and R. S. B. Ong, Effects of energetic heavy ions on electromagnetic ion cyclotron wave generation in the plasmapause region, J. Geophys. Res., 89, 2217-2233, 1984.

Meinel, The spectrum of the airglow and the aurora, Reports on Progress in Physics, 14, 121-146, 1951.

Moshupi, M. C., C. D. Anger, J. S. Murphree, D. D. Wallis, J. H. Whitteker, and L. H. Brace, Characteristics of trough region auroral patches and detached arcs observed by Isis 2, J. Geophys. Res., 84, 1333-1346, 1979.

Shiokawa K., Y. Katoh, M. Satoh, M. K. Ejiri, T. Ogawa, T. Nakamura, T. Tsuda, and R. H. Wiens, Development of optical mesosphere thermosphere imagers (OMTI), Earth Planets Space, 51, 887-896, 1999.

Shiokawa K., Y. Katoh, M. Satoh, M. K. Ejiri, T. Ogawa, Integratingsphere calibration of all-sky cameras for nightglow measurement, Adv. Space Sci., 26, 1025-1028, 2000. 
Spasojevic, M., H. U. Frey, M. F. Thomsen, S. A. Fuselier, S. P. Gary, B. R. Sandel, and U. S. Inan, The link between a detached subauroral proton arc and a plasmaspheric plume, Geophys. Res. Lett., 31, 4803-4806, 2004.

Vegard L., Hydrogen showers in the auroral region, Nature, 144, 1098, 1939.

Vegard L., Emission spectra of the night sky and aurora, report of the Gassiot Committee, 82 pp., Phys. Soc. of London, London, 1948.

Yahnina, T. A., A. G. Yahnin, J. Kangas, J. Manninen, Proton precipitation related to Pc 1 pulsations, Geophys. Res. Lett., 27, 3575-3578, 2000.

Yahnina, T. A., A. G.Yahnin, J. Kangas, and J. Manninen Lacalized enhancements of energetic proton fluxes at low altitudes in the subsuroral region and their relation to the Pc1 pulsations, Cosmic Research, 40, 213-223, 2002.

Yizengaw, E., H. Wei, M. B. Moldwin, D. Galvan, L. Mandrake, A. Mannucci, and X. Pi, The correlation between mid-latitude trough and plasmapause Geophys. Res. Lett., 32, 10102, 2005.

Wallis, D. D., et al., Observations of particles precipitating into detached arcs and patches equatorward of the auroral oval, J. Geophys. Res., 84, 1347, 1979. 


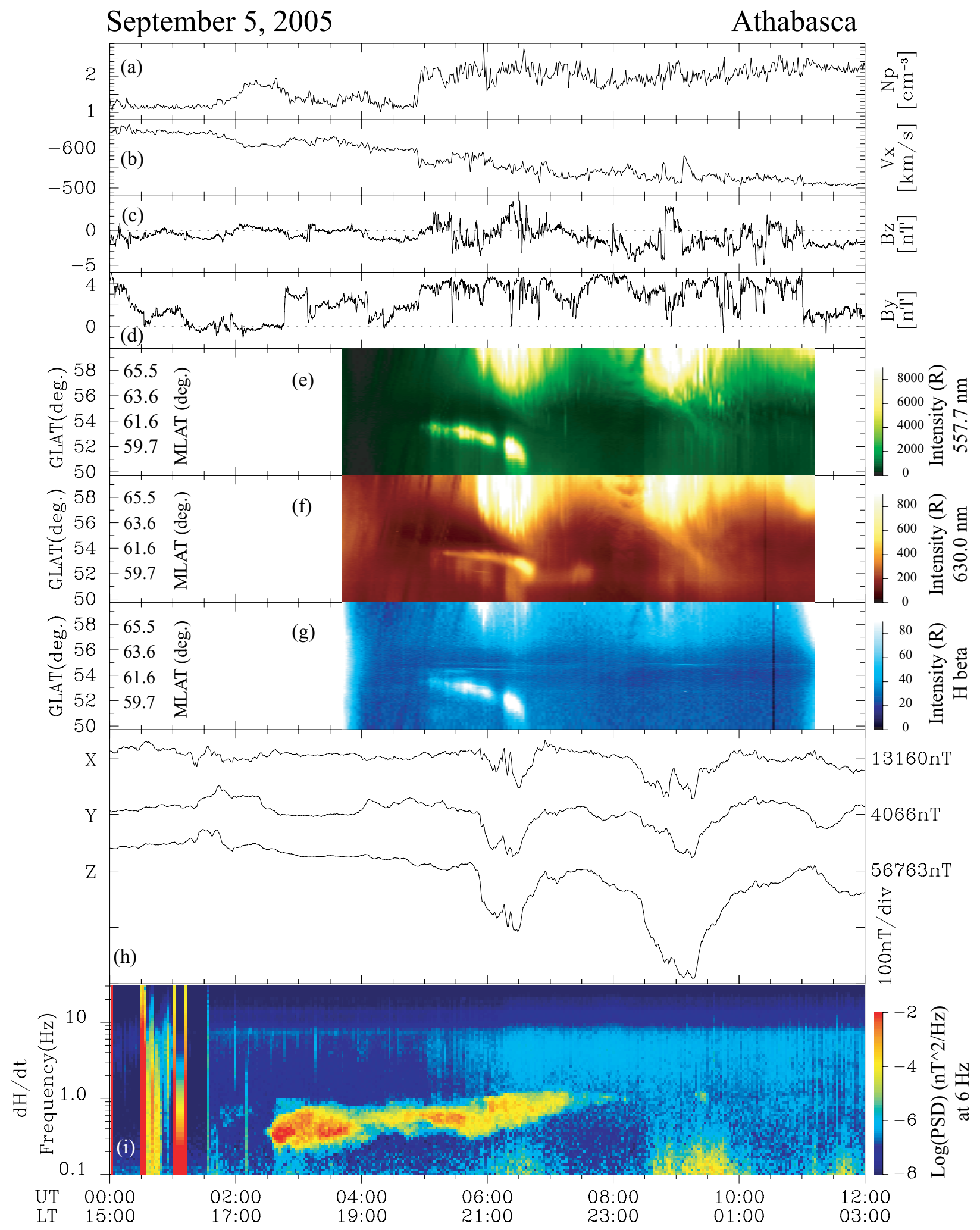

Figure 1. From top to bottom, proton density $\left[\mathrm{cm}^{-3}\right]$, GSM-X component of solar wind velocity $[\mathrm{km} / \mathrm{sec}]$, and GSM-Z and GSM-Y components of IMF variations obtained by the ACE spacecraft, variations of auroral intensity at $557.7 \mathrm{~nm}, 630.0 \mathrm{~nm}$, and $\mathrm{H} \beta$ in a north-south

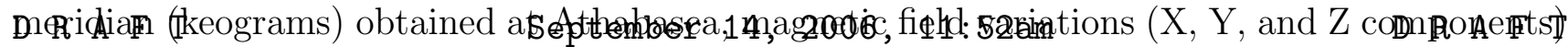
obtained at Meanook near Athabasca, and dynamic spectrum of $\mathrm{H}$ component geomagnetic field variations, obtained at Athabasca on 5 September, 2005 
September 5, 2005 04:56:02 UT

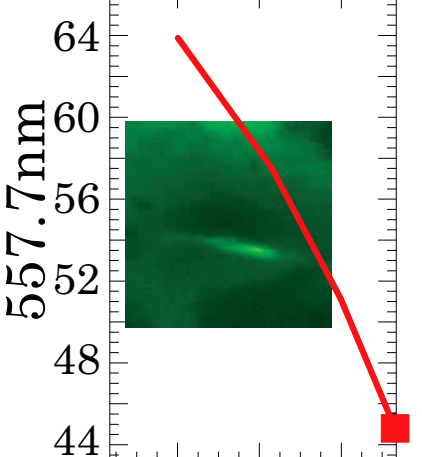

244248252

04:56:14 UT

64

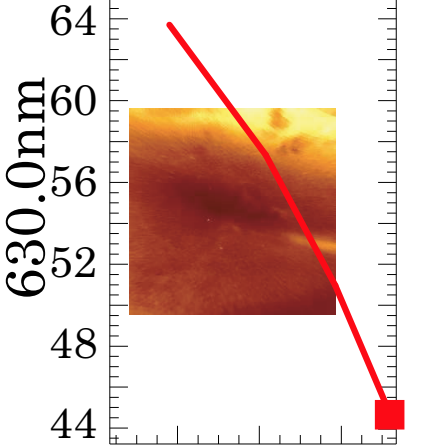

244248252

04:56:36 UT

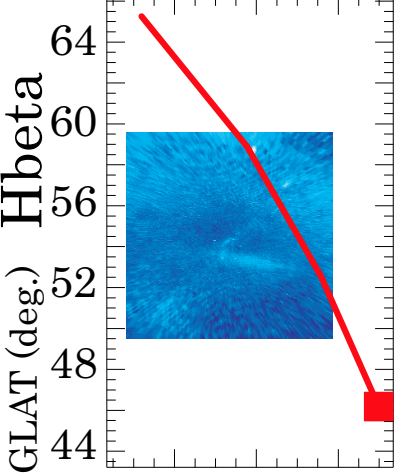

244248252 GLON (deg.)
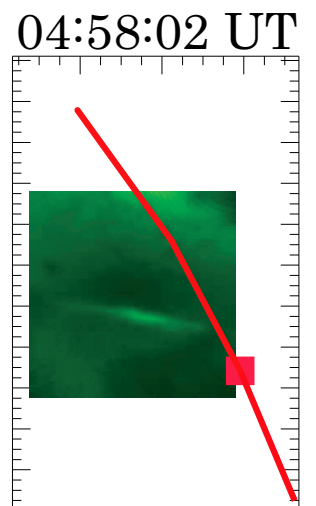

244248252
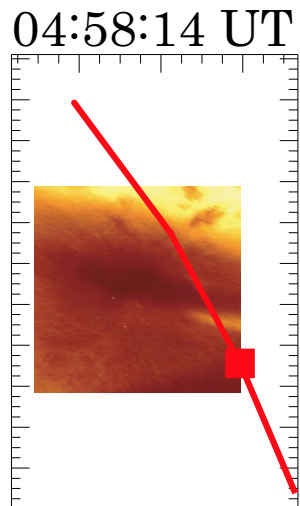

244248252
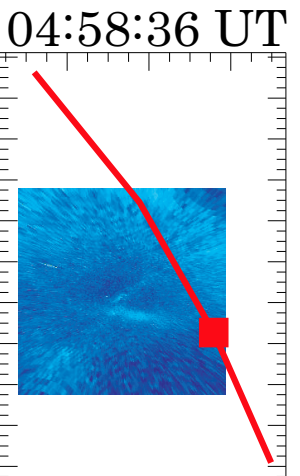

244248252 site : Athabasca

05:00:02 UT 05:02:02 UT

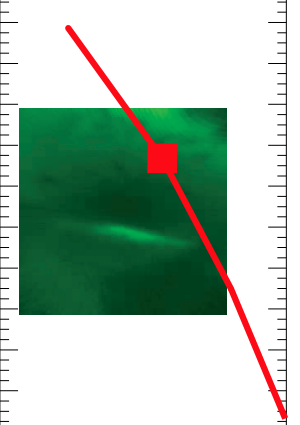

244248252

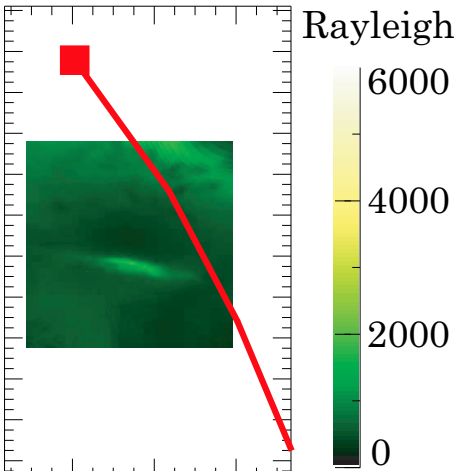

244248252

05:00:14 UT 05:02:14 UT

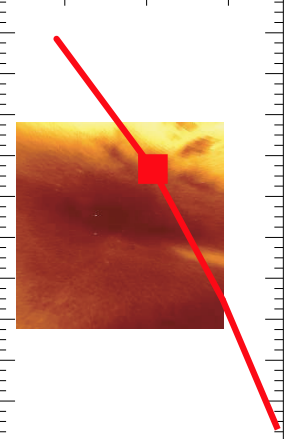

244248252

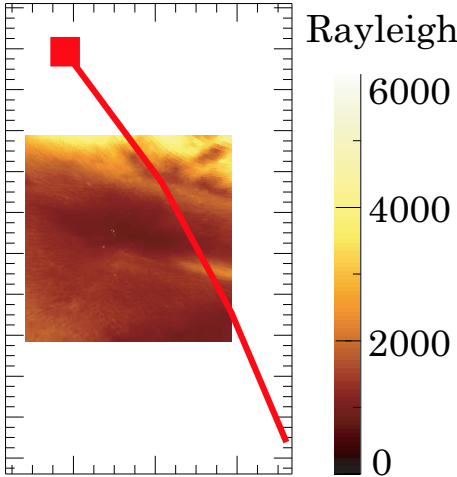

244248252
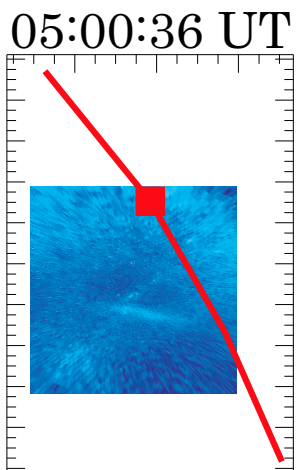

244248252
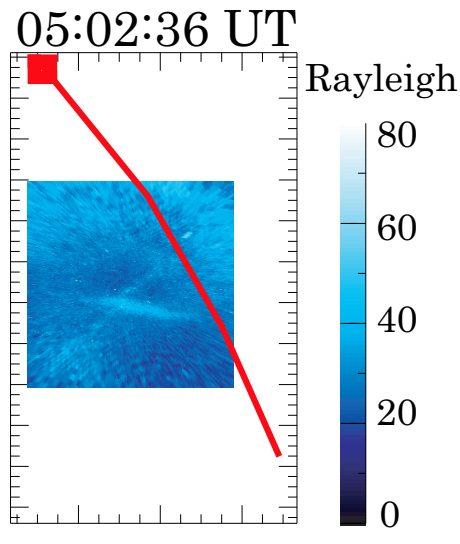

244248252

Figure 2. Sequential auroral images obtained at Athabasca on 5 September, 2005. The red squares and lines indicate the footprints and the tracks of the NOAA 17 satellite 


\section{September 5, $2005 \quad$ NOAA 17}

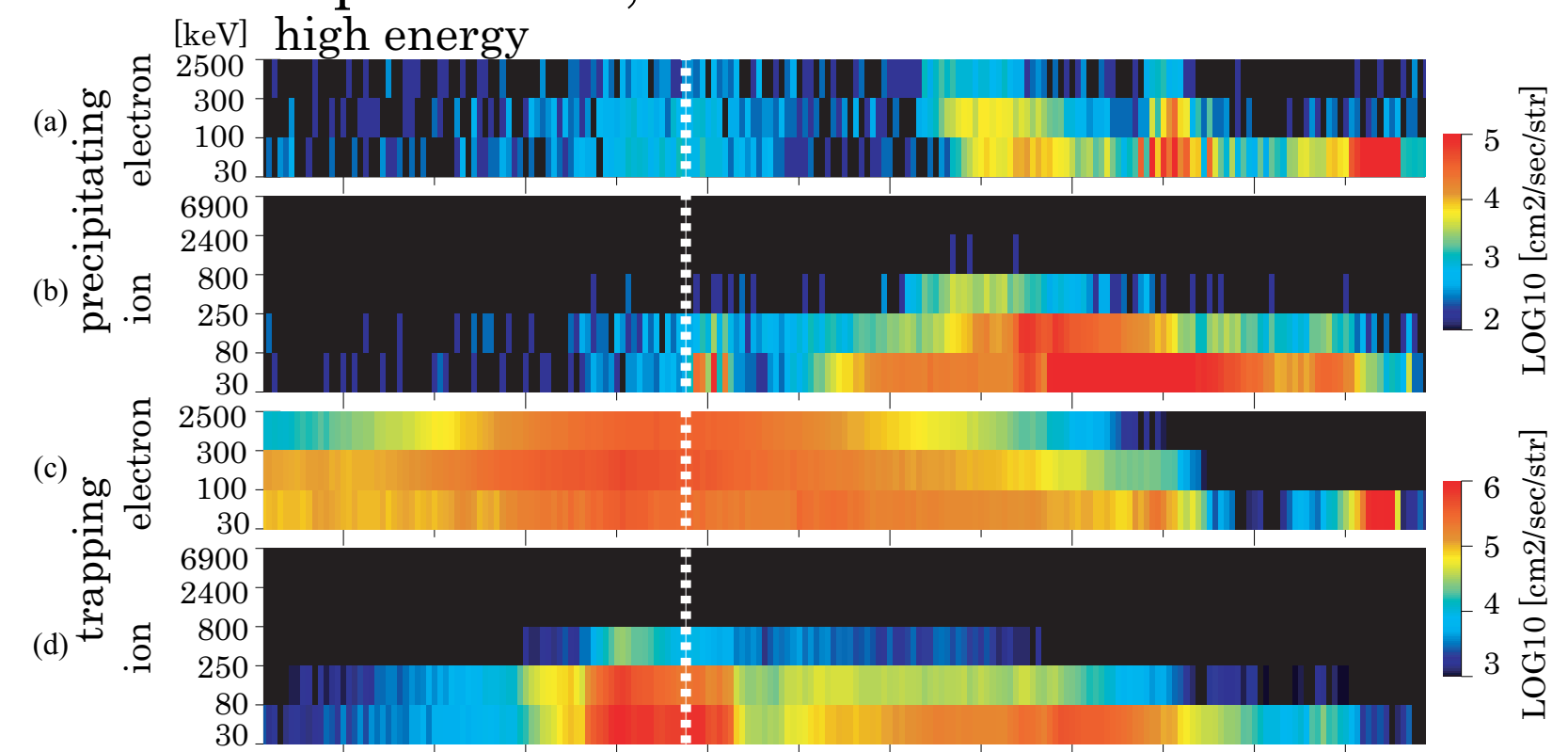

[eV] low energy

(e)

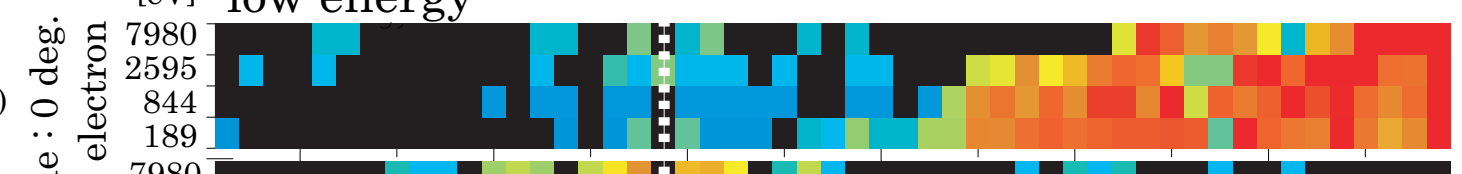

(f)

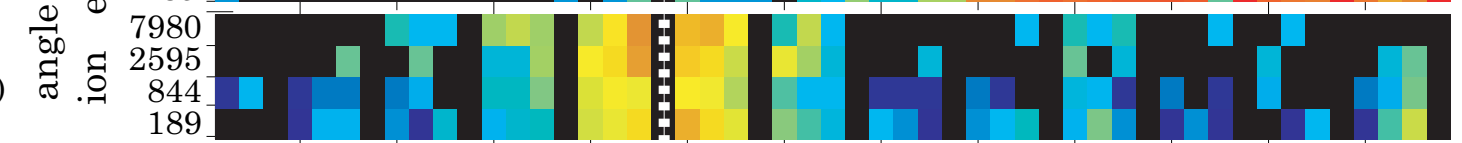

(g)

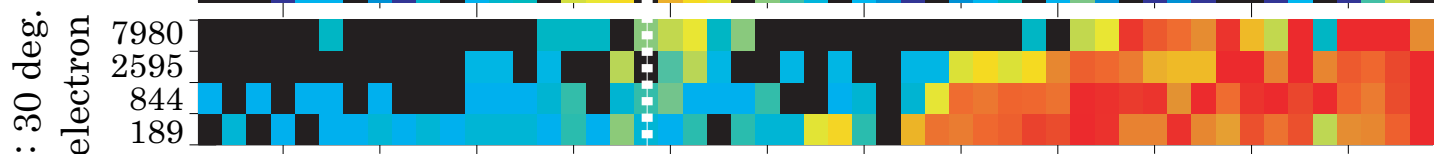

(h)

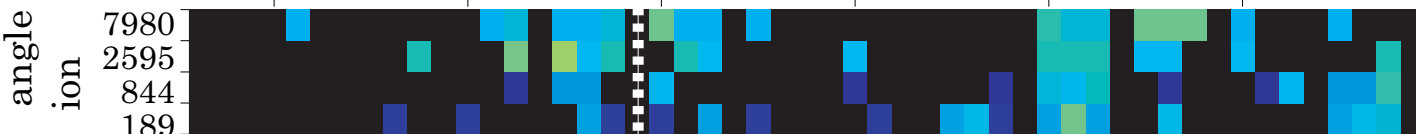

UT:04:56:36 04:57:40 04:58:44 04:59:48 $05: 00: 52 \quad 05: 01: 56$

$\begin{array}{rcccccc}\text { GLON : } & 253.4 & 252.0 & 250.4 & 248.5 & 246.3 & 243.6 \\ \text { GLAT : } & 44.3 & 48.0 & 51.7 & 55.4 & 59.0 & 62.6 \\ \text { MLAT : } & 54.8 & 58.0 & 61.1 & 64.2 & 67.1 & 69.9 \\ \text { MLT : } & 22.1 & 22.0 & 21.8 & 21.7 & 21.5 & 21.2 \\ \text { L value : } & 3.1 & 3.6 & 4.4 & 5.3 & 6.7 & 8.6\end{array}$

Figure 3. From top to bottom, precipitating $\left(\sim 70^{\circ}\right.$ to the horizonal plane $)$ and trapped $\left(\sim 10^{\circ}\right.$

to the horizonal plane) electron and ion spectra at energies of 30-2500 keV (electrons) and 30$6900 \mathrm{keV}$ (ions) and precipitating electron and ion spectra at energies less than $20 \mathrm{keV}$ at angles of $\sim 75^{\circ}$ and $\sim 50^{\circ}$ to the horizontal plane, observed by the NOAA 17 satellite on 5 September, 2005. The white dashed line indicates the time when the NOAA 17 satellite crossed the arc. 


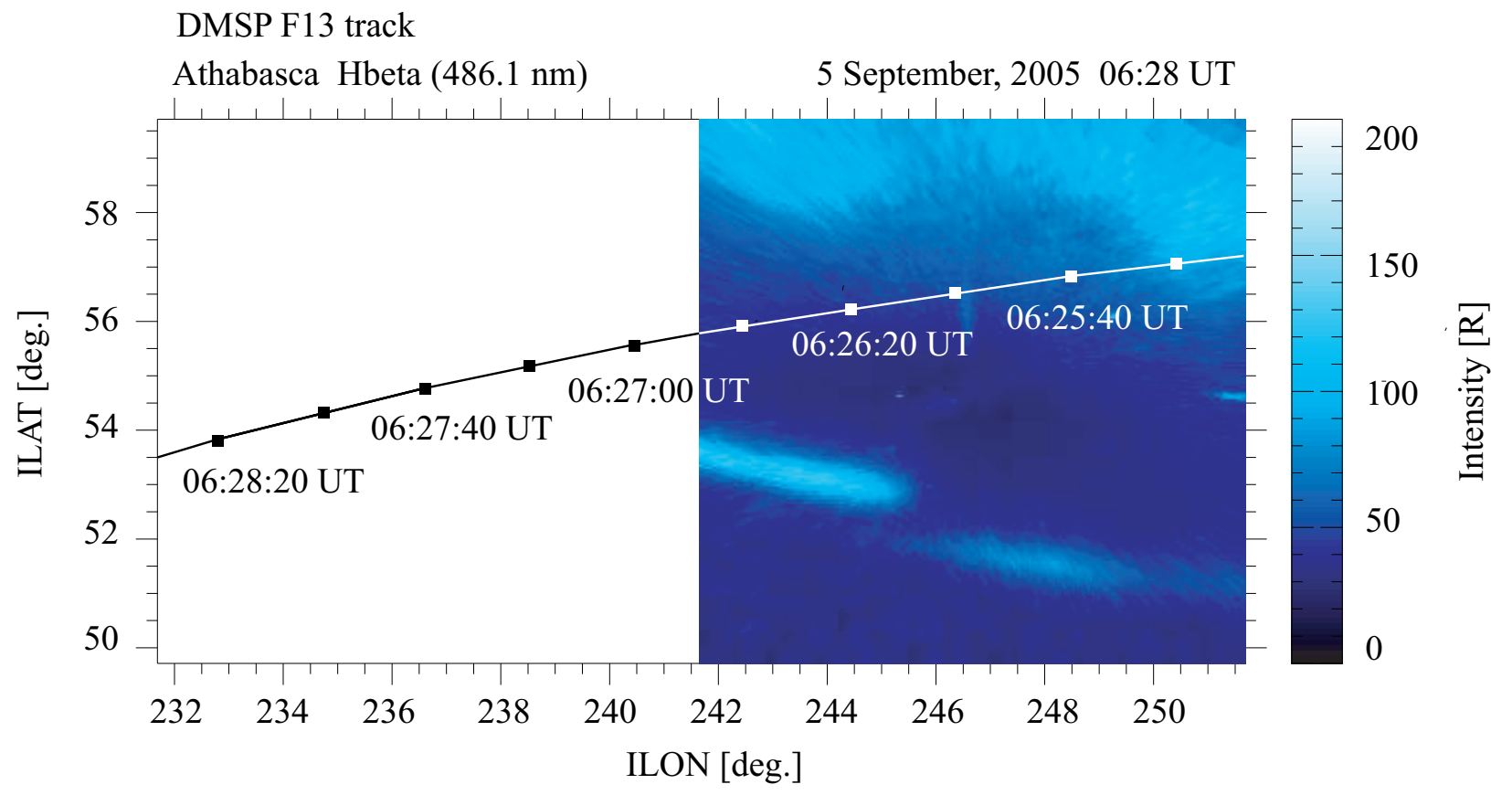

Figure 4. The $\mathrm{H} \beta$ arc image obtained at Athabasca at 0628:00 UT with the DMSP F13 satellite footprints mapped from the southern hemisphere. The IGRF-2005 model was used to map the satellite location to the conjugate hemisphere. The line and the squares indicate the track and footprints of the DMSP F13 satellite, every 20-min at an altitude of 120-km. 


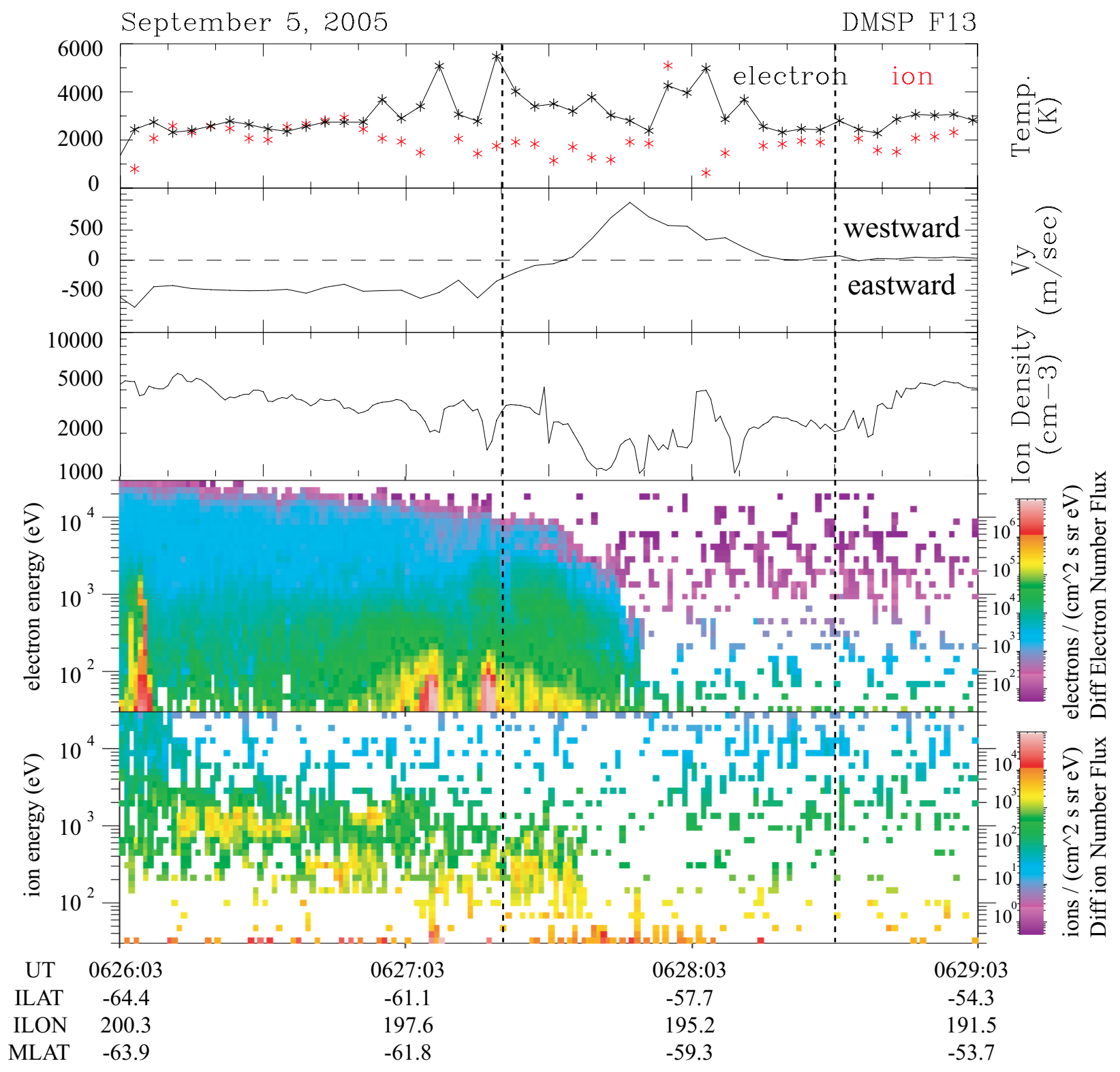

Figure 5. From top to bottom, electron and ion temperatures, ion drift velocity perpendicular to the satellite track, ion density, and precipitating electron and ion energy spectra obtained by the DMSP F13 satellite at an altitude of $840 \mathrm{~km}$. The time interval of possible arc crossing in Figure 4 is shown by the two vertical dashed lines. 